\title{
Mapping of Sea Water Intrusion in the Western Libyan Coast Using Geo-electrical Method: Case Study
}

\author{
Abdel Hameed M. Salem ${ }^{1 *}$, Magdi A. Mountasir ${ }^{2}$, Husam Abdussalam R. Shames ${ }^{3}$ \\ ${ }^{1,3}$ Prospecting department, The Libyan Atomic Energy Establishment, Tripoli, Libya \\ ${ }^{2}$ Scientific and technical matters department, Higher Institute for Sciences and Technology, \\ Algaraboulli, Libya
}

DOI: https://doi.org/10.21467/proceedings.4.8

* Corresponding author email: Hameed.ehtman @ gmail.com

\begin{abstract}
As most of the Libyan population live in the north side of the country; mainly in the western coastal zone; the sea water intrusion is a vital phenomena that need to be studied to locate, measure its diffusion rate, and take a remediation actions [1]. Conventionally, water sampling of ground water wells is used to evaluate sea water intrusion in coastal areas [2]. Nevertheless, excessive use and cost of drilling should be avoided by relaying on advanced technologies [2]. Geo-electrical methods such as electrical resistivity and electromagnetic can be used for studying sub surface geophysics from the earth surface with no need for drilling, and can give a trusted results [3]. The huge contrast in resistivity between saline and fresh water makes measurement of the resistivity in the ground a useful technique for detecting and delineate the saline interface, consequently, using the electrical resistivity method is a successful technology for studying sea water intrusion [3]. Mapping sea water intrusion in a selected area located in the western coast of Libya is reported by this study, it covers about $120 \mathrm{Km}^{2}$ from Algrabouli to Elallus by 16 profiles perpendicular to shoreline with total number of 53 vertical electric sounding (VES). This study is considered as a case study to insure the need to cover the whole Libyan coast with more detailed studies, furthermore, it concluded that the sea water intrusion in Libya is truly a serious issue that will lead to pollute the groundwater in the coastal areas with salt and costal contaminated water in the case of not correcting the situation.
\end{abstract}

Keywords: Seawater intrusion in the western Libyan coast; Geo-electrical method to study sea water intrusion; Case study of sea water intrusion by electrical resistivity method.

\section{Introduction}

The phenomenon of sea water Intrusion occurs in coastal areas where the different densities of both the saltwater and freshwater allow the seawater to intrude into the freshwater aquifer. Equally important to the salinization of fresh water, the intruded seawater may be contaminated with sewage water [2].

(C) 2018 Copyright held by the author(s). Published by AIJR Publisher in Proceedings of First Conference for Engineering

Sciences and Technology (CEST-2018), September 25-27, 2018, vol. 2 .
This is an open access article under Creative Commons Attribution-NonCommercial 4.0 International (CC BY-NC 4.0) license, which permits any non-commercial use, distribution, adaptation, and reproduction in any medium, as long as the original work is properly cited. ISBN: 978-81-936820-6-7 
For countries like Libya, that have coasts and their main resource of freshwater is the groundwater, a high potential of seawater intrusion exist in the coastal areas threatening the freshwater aquifer with salinization and contamination [1].

Before the improvements of geophysical methods to be used for geo-environmental investigations, water sampling was the only way to locate seawater intrusion. The need for a sufficient geo-environmental investigation techniques was high for areas where no wells exist. Drilling new wells to study seawater intrusion was not always applicable, economic and friendly to the environment [3]. Today, many geophysical methods such as geo-electrical are used to investigate seawater intrusion. These techniques deals with the electrical condition of earth and it investigate electrical properties of rocks and minerals under different geological circumstances.

Many studies world wide used electrical resistivity method for mapping the seawater intrusion for coastal areas [4], some of these studies in Europe are: Oteri [5] has delineated saline water intrusion in England since 1983. Antonio Satriani et al [6] have studied on Characterization of the Coastal Saltwater Intrusion in Metapontum Reserve Forest in Southern Italy. Soldal et al [7] have done Seawater in western Norway. Nowroozi et al [8] have carried out a study on saltwater intrusion into the freshwater aquifer in the eastern shore of Virginia (USA) by electrical resistivity survey using Schlumberger configuration. Abdul Nassir et al [9] have delineated and mapped the intrusion boundary between fresh water and saline water in northwest of Malaysia by geoelectrical imaging surveys. Shaaban F.F[10] has employed Vertical electrical soundings (VES) in a coastal area of north western Egypt. Sheriff et al [11] have carried out Geoelectrical studies for delineating seawater intrusion in UAE. Abdulaziz M. et al [12] have conducted seawater intrusion in southwest of Saudi Arabia. This study aims to map the seawater intrusion in around $120 \mathrm{Km}^{2}$ area between Algarboulli and Elallus at the western Libyan coast.

\section{Study Methodology}

\subsection{The Scientific Theory}

There are a high distinguish between saline and fresh water in resistivity, this difference made the measurement of the resistivity for the ground water a useful technique for detecting and delineating the saline interface. Knowing the formation resistivity will directly lead to appoint the total dissolved salt of ground water. The relation between formation resistivity and groundwater quality is demonstrated in Table 1. [2].

\subsection{Data Acquisition}

One of most used geophysical techniques for studying formation resistivity is the electrical resistivity method [2]. The main frequent used types of measurement are Vertical Electric Sounding (VES) and resistivity profiling [3]. A proper number of VES should be carried out in the survey area along on profiles perpendicular to shoreline. In this study, schlumberger

Proceedings of First Conference for Engineering Sciences and Technology (CEST-2018), vol. 2 
Mapping of Sea Water Intrusion in the Western Libyan Coast Using Geo-electrical Method: Case Study

configuration has been adapted with maximum current electrode spacing of $400 \mathrm{~m}$ as illustrated in Figure 1. In this technique the electrical current by two electrodes AB is stepwise made to flow through deeper and deeper parts of the ground, otherwise the distances between the potential electrodes $\mathrm{MN}$ almost fixed. To measure apparent resistivity to subsurface layers, a resistivity meter (Saris) is used with equation (1).

$$
\rho_{\alpha}=\frac{\pi\left(s^{2}-a^{2} / 4\right)}{a} \frac{\Delta V}{i}
$$

Where: $\rho a=$ apparent resistivity, ohm- $\mathrm{m} ; a=\mathrm{MN}$ distance, $\mathrm{m} ; \mathrm{s}=\mathrm{AB}$ distance, $\mathrm{m} ; \mathrm{v}=$ Voltage, volt; $i=$ current, amp.

Table 1: Relation between formation resistivity and groundwater quality

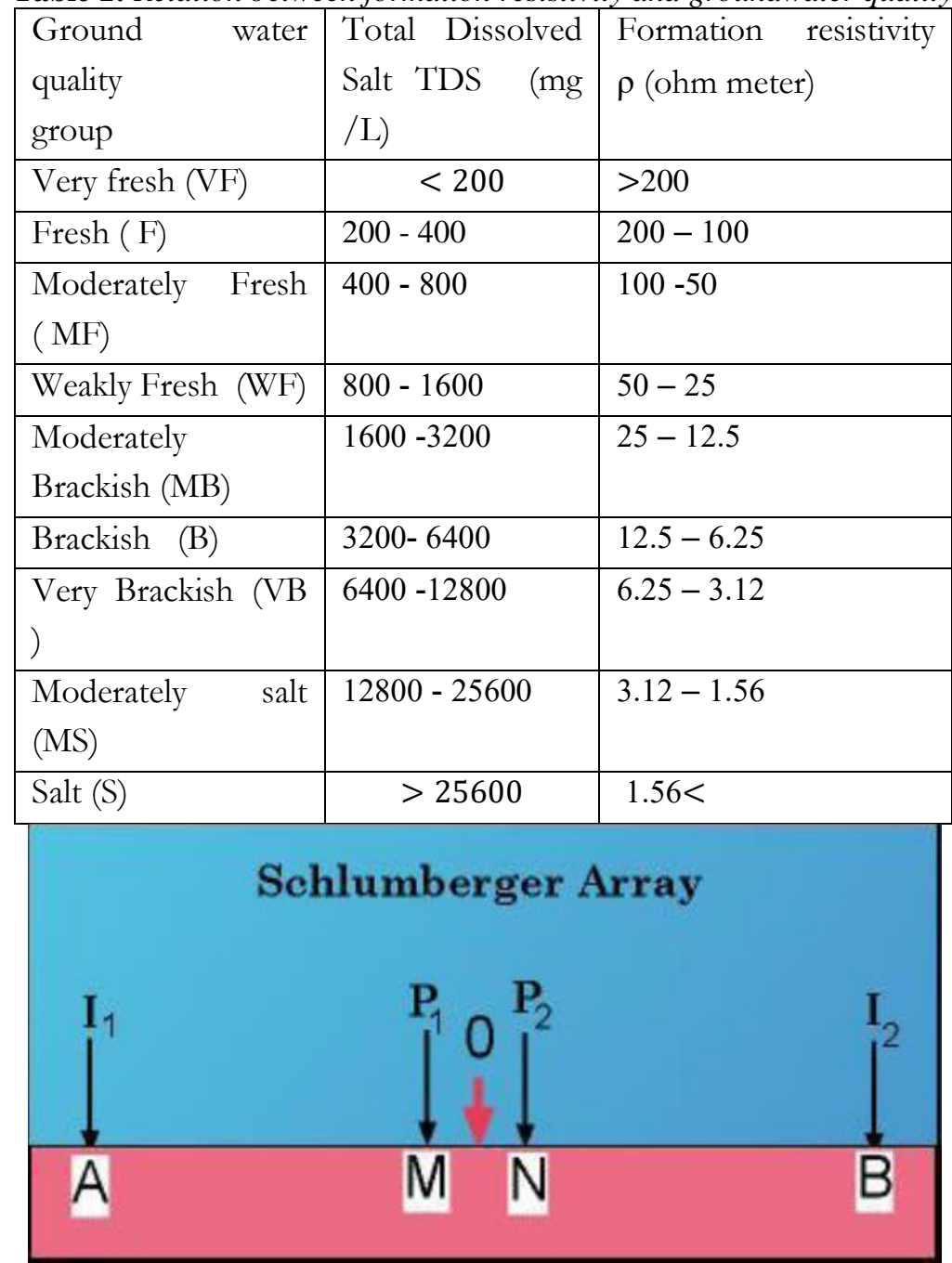

Figure 1: Schlumberger array. 


\subsection{Data Processing and Interpretation}

The VES curves were analyzed using the available software program (IpI2Win+ip) to generate pseudo cross sections, these sections shows distribution of resistivity with the depth. A resistivity values of less than 10 Ohm meter appears as dark blue and black color in the figures which means, depending on "Tab. 1", they were affected by sea water intrusion into ground water aquifer.

Iso- apparent resistivity maps were plotted by the help of the software (Oasis Montaj). These maps indicate distribution of apparent resistivity in the area against distance of current electrodes $(A B)$ at a fixed depth. The depth was practically almost between $(A B / 3, A B / 4)$.

\section{The Case Study}

\subsection{Location of the Study Area}

The study area is located approximately $60 \mathrm{~km}$ East of Tripoli. The site covers an area of about $120 \mathrm{~km}^{2}$. It is bounded on the north by the Mediterranean Sea, and situated between Algarboulli and Elallus Figure 2. It lies between latitudes (32 $\left.46^{\prime} 57.10^{\prime \prime} \mathrm{N}, 32^{\circ} 43^{\prime} 38.99^{\prime \prime} \mathrm{N}\right)$, and longitudes $\left(13^{\circ} 41^{\prime} 32.70^{\prime \prime} \mathrm{E}, 1^{\circ} 0^{\prime} 20.17^{\prime \prime} \mathrm{E}\right)$.

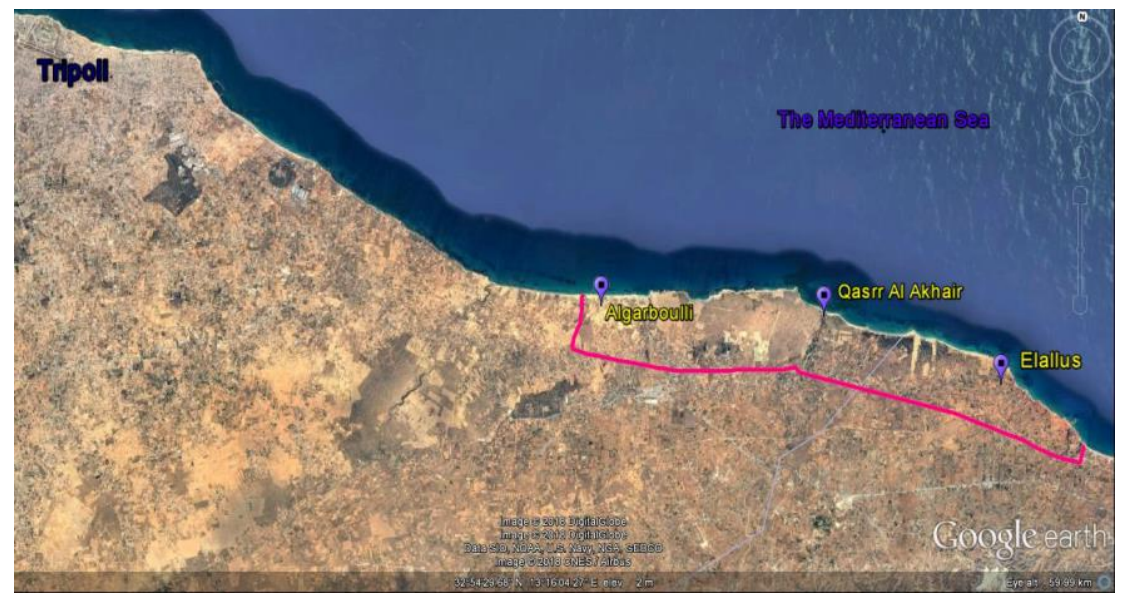

Figure 2: Location of the study area.

\subsection{Distribution of the Vertical Electrical Soundings and Profiles on the Study Area}

The survey was accomplished with Fifty three VES configuration with a maximum current electrode spacing (AB) of four hundred meters. A sixteen pseudo cross sections perpendicular to the shore line were selected as illustrated in Figure 3. 
Mapping of Sea Water Intrusion in the Western Libyan Coast Using Geo-electrical Method: Case Study

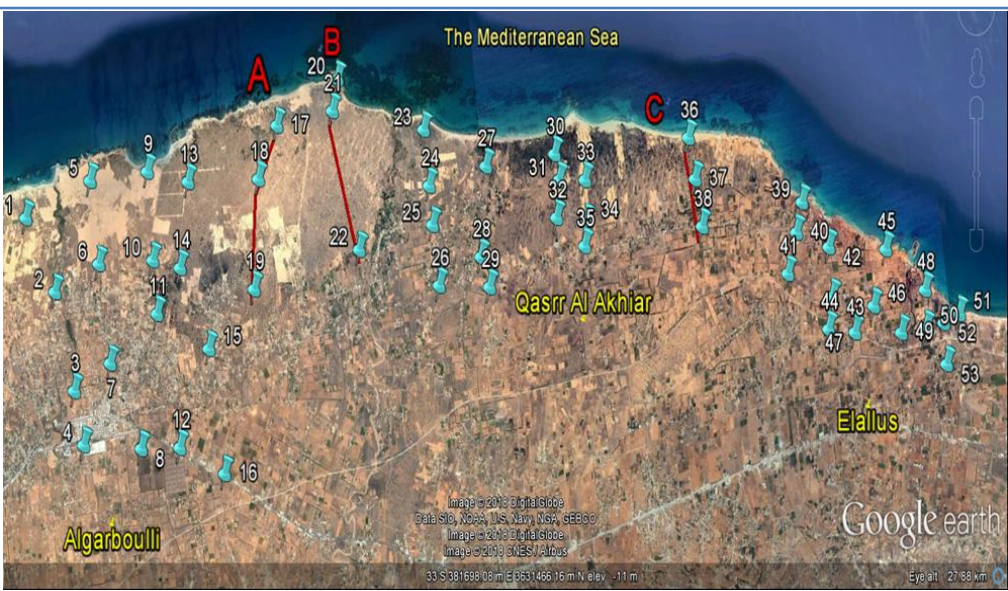

Figure 3: Distribution of the VES's and profiles on the study area.

\section{$4 \quad$ Results and Discussions}

\subsection{Results Gained by (Ip I2wint +Ip) Software}

As mentioned before, all sixteen pseudo cross sections have been processed using (Ip I2wint +Ip) software to show the distribution of resistivity with depth. Only three pseudo cross sections (referred to as A, B and C in Figure 3) have been selected as examples for these results in this paper. For cross section A Figure 4, the resistivity values ranged between (18 $60 \mathrm{Ohm}$ meter) at almost 75 meter depth which means there is no present of seawater intrusion according to Table 1. For resistivity obtained in Profile B, the lowest values ranged between $(10-16$ Ohm meter) at VESs $(21,22)$ to clearly indicate it was slightly effect by Sea water intrusion Figure 5. In cross section C, The lowest resistivity was located at VES 36 with (0-10 Ohm meter) value to declare the area as a highly effected by seawater intrusion Figure 6.

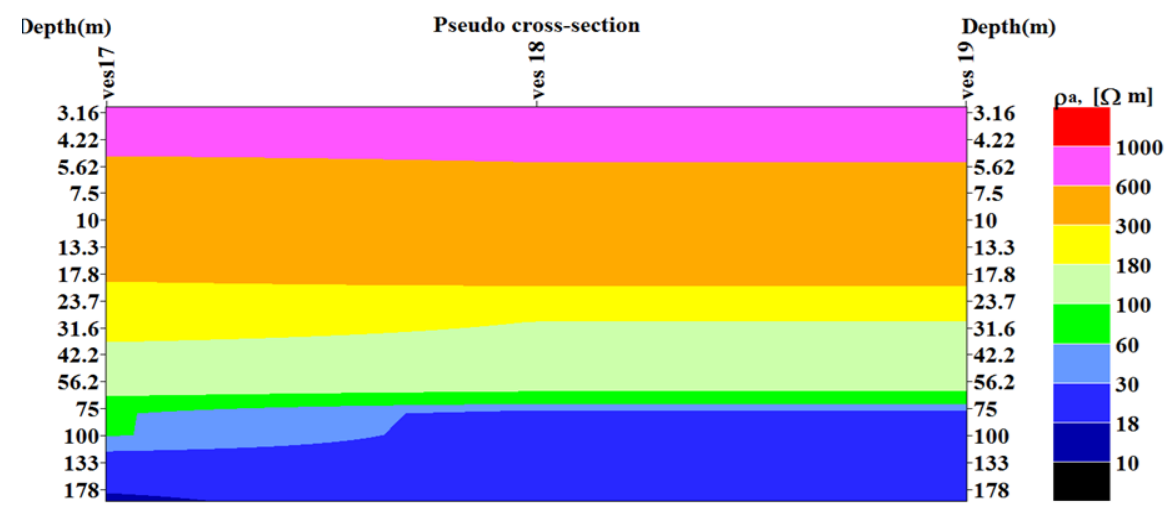

Figure 4: Profile A (VES's: 17, 18, 19). 
Salem et al., CEST-2018, AIJR Proceedings 4, pp.411-421, 2018

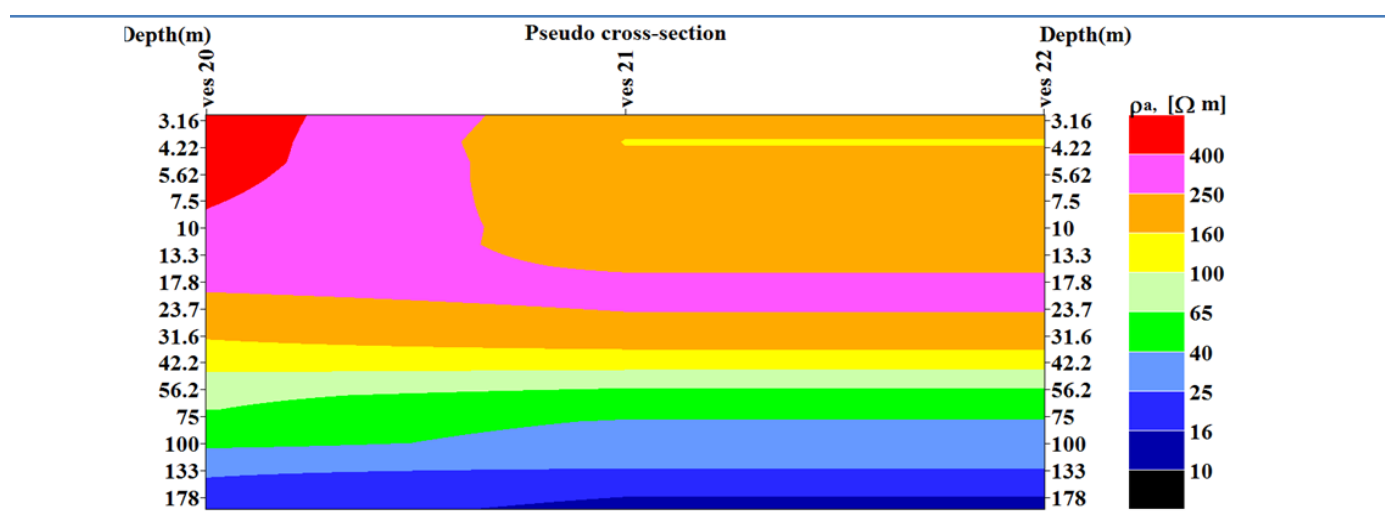

Figure 5: Profile B (VES's: 20, 21, 22)

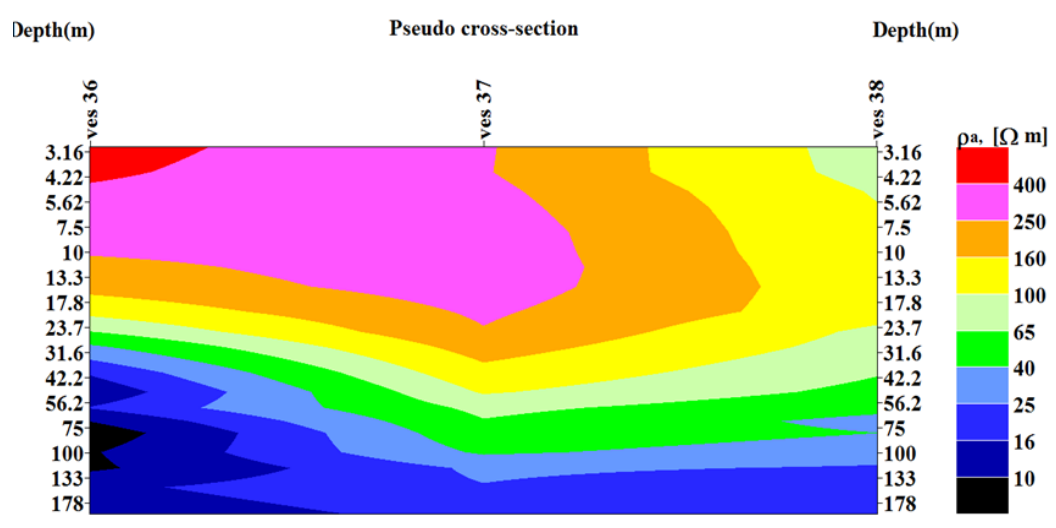

Figure 6: Profile C (VES's: 36, 37, 38)

\subsection{Results Gained by Oasis Montaj Software}

Three Iso-apparent resistivity maps have been generated to reflect lateral variation of apparent resistivity at a certain depth using the Universal Transverse Mercator (UTM) coordinate system, these maps indicate distribution of apparent resistivity in the area against distance of current electrodes (AB). The used AB values were: 200, 300 and 400 meters. In all three maps, the lowest resistivity values of less than $(10 \mathrm{Ohm}$ meter) were gained in certain VES's to specify the presence of seawater intrusion.

The iso-apparent resistivity map for $\mathrm{AB}=200$ meter at about (50 to 70 meters depth) are shown in Figure 7. , the lowest resistivity values were obtained at VESs (6, 7, 11, 30, 36, 51, 52). 
Mapping of Sea Water Intrusion in the Western Libyan Coast Using Geo-electrical Method: Case Study

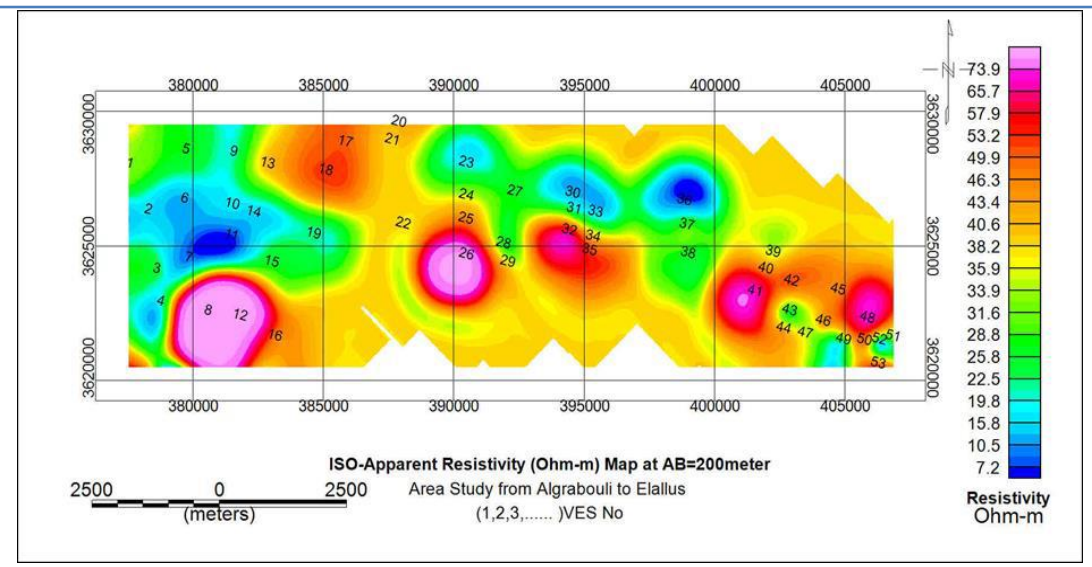

Figure 7: Iso-apparent resistivity map for $\mathrm{AB}=200 \mathrm{~m}$.

Figure 8 illustrated the iso-apparent resistivity map for $\mathrm{AB}=300$ meter at an approximate depth of (75 to 100) meters. the lowest resistivity values presented at VES's $(3,5,6,7,10,11$, $14,23,24,30,31,33,36)$.

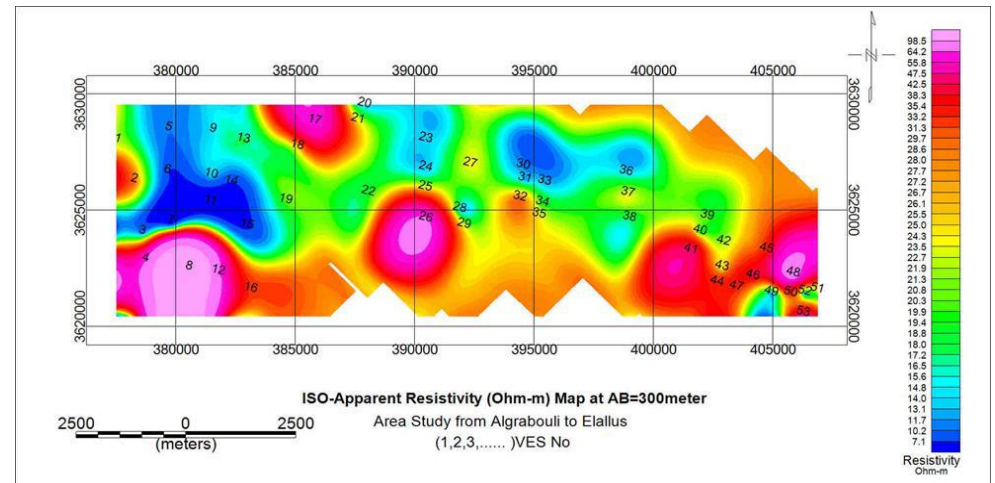

Figure 8: Iso-apparent resistivity map for $\mathrm{AB}=300 \mathrm{~m}$.

The map in Figure 9 shows iso-apparent resistivity for $\mathrm{AB}=400$ meter with almost ( 100 to 130) meters depth. the lowest resistivity values were considered at VES's $(2,7,8,11,14,23$, $25,27,28,30,33,34,36,51,52)$. 


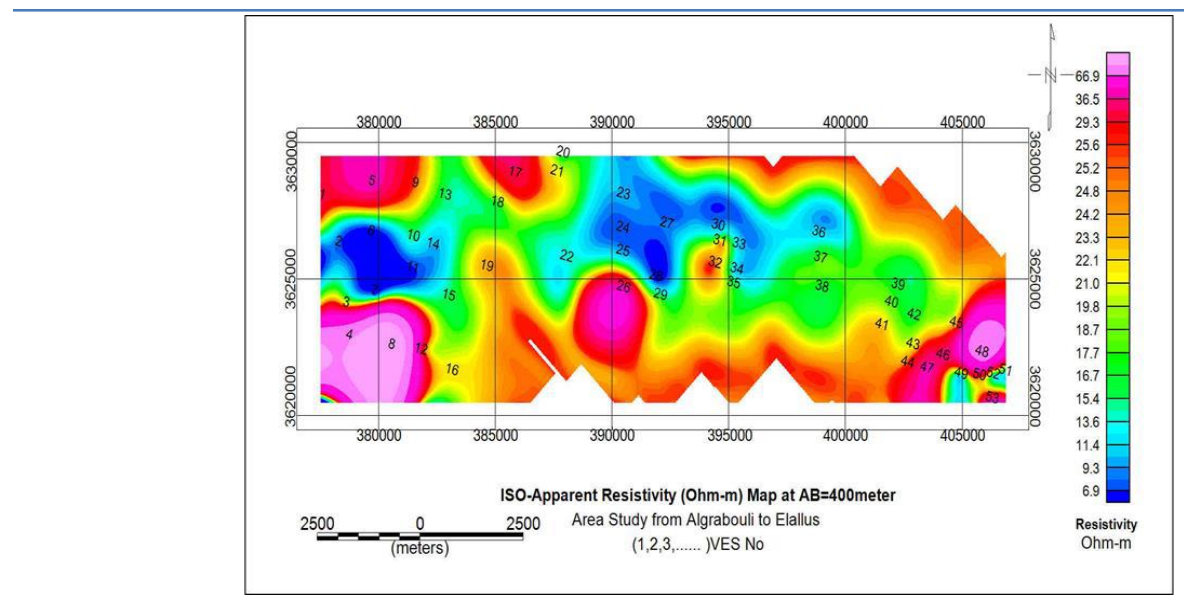

Figure 9: Iso-apparent resistivity map for $\mathrm{AB}=400 \mathrm{~m}$.

\subsection{Mapping Seawater Intrusion in Western Libyan Coast}

The interface between salt and fresh water is identified in the study area approximately as a red line in Figure 10. This map is evidently demonstrate and prove the occurrence of seawater intrusion in the area.

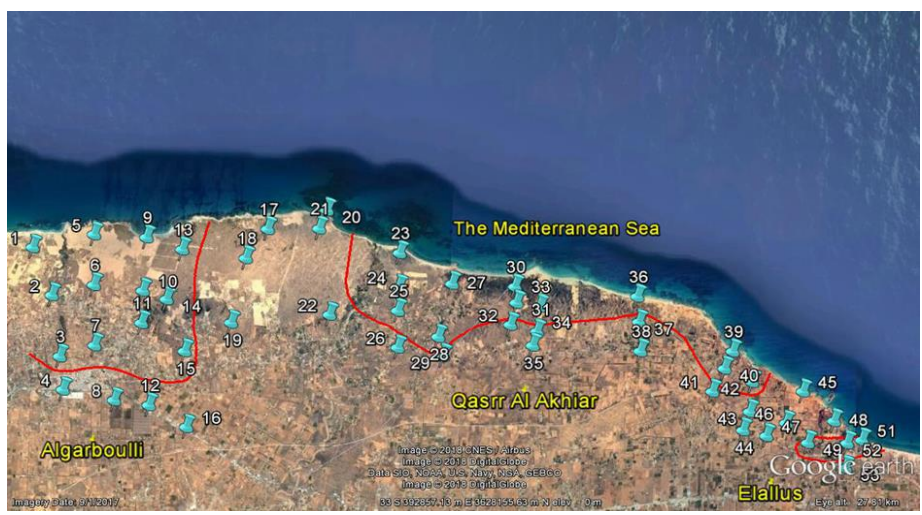

Figure 10: Mapping seawater intrusion in Western Libyan Coast.

\section{Controlling and Minimizing Seawater Intrusion}

Methods for controlling intrusion vary widely depending on the source of the saline water, the extent of intrusion, local geology, water use and economic factors. There are several methods for controlling seawater intrusion demonstrated with its advantages and disadvantages as follows: [13]

1- Reduction of pumping rates: needs public awareness with recycling and reuse of water. Advantages: reduction of abstraction rate. Disadvantages: private stockholders, temporary solution. 
Mapping of Sea Water Intrusion in the Western Libyan Coast Using Geo-electrical Method: Case Study

2- Relocation of pumping wells: movement of wells in more inland position. Advantages: decrease the occurrence of upconing of salt water. Disadvantages: costly, temporary solution, obstruction in relocation

3- Use of Sub surface Barriers: Reduce the permeability of aquifer; Sheet piling, Cement grout, or Chemical grout. Advantages: Reduce the intrusion of saline water. Disadvantages: Not efficient for deep aquifers, and costly.

4- Natural Recharge: Constructing dams and weirs to prevent the runoff from flowing to the sea. Advantages: Prevent the runoff to flow directly to the sea. Disadvantages: Depends on the soil properties, Take Long time, Unsuitable for confined and deep aquifers.

5- Artificial Recharge: Increase the ground water levels, using surface spread for unconfined aquifers and recharge wells for confined aquifers. Advantages: Increase the groundwater storage. Disadvantages: Ineffective in the areas where excessive ground water pumping occurs, Occupies a large area.

6- Abstraction of Saline Water: Reduce the volume of saltwater by extracting brackish water from the aquifer and returning to the sea. Advantages: Decreases the volume of saline water, Protects pumping wells from upconing. Disadvantages: private stockholders, temporary solution.

The best methodology to reduce the seawater intrusion in coastal aquifers is: Abstraction, Desalination and Recharge (ADR) [14]. This methodology aims to overcome all or at least most of the limitations of the previous methods. ADR consists of three steps; abstraction of brackish water from the saline zone, desalination of the abstracted brackish water using reverse osmosis ( $\mathrm{RO})$ treatment process and recharge of the treated water into the aquifer as shown in Figure 11. The reason of ranking this method as the best to control seawater intrusion is its unique ability to produce freshwater by using the saline groundwater which will directly lead to push the intrusion line back to the sea. The main disadvantage of this technique is the bad environmental effect resulted by using traditional energy sources. 


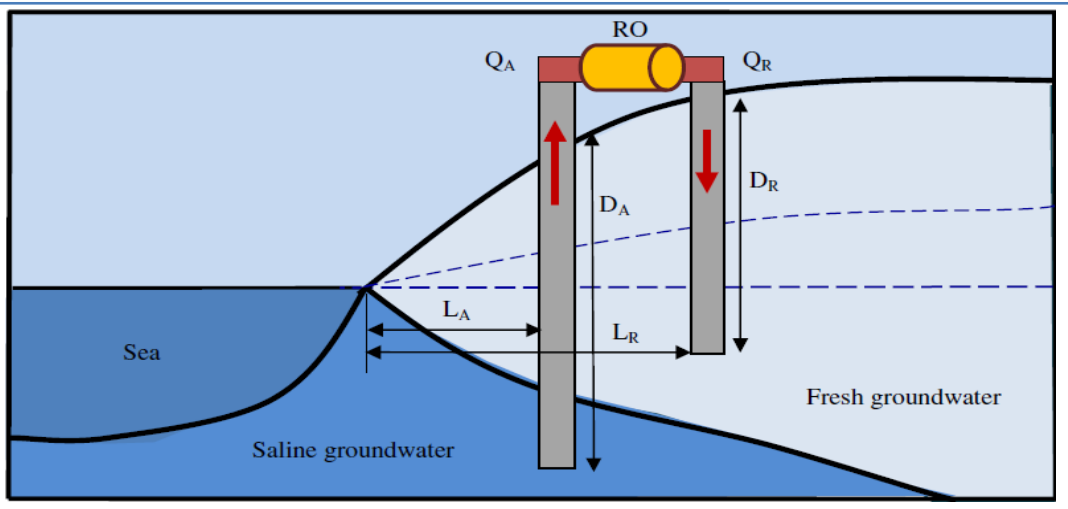

Figure 11: Diagram of the ADR Methodology.

\section{Conclusion and Recommendations}

- This paper was accomplished with Fifty three VES configuration with a maximum current electrode spacing (AB) of four hundred meters and sixteen pseudo cross sections perpendicular to the shore line were selected. The study evidently indicated the existence of seawater intrusion in the study area that covers about $120 \mathrm{Km}^{2}$ between Algrabouli and Elallus, moreover, highly express the need to map the whole country to precisely locate this phenomena.

- Establishing a national project to map ground water contamination for the whole shore line in Libya by using the electrical resistivity method to investigate the seawater intrusion.

- Using Abstraction, Desalination and Recharge (ADR methodology) to solve the problem of seawater intrusion in Libya depending on the national map for coastal ground water contamination.

- Using clean energy in desalination plants used for ADR methodology.

- Nuclear energy should be considered as one of the best choices when selecting the most proper energy technology for ADR and seawater desalination in Libya.

\section{Acknowledgment}

The authors would like to thank The Libyan Atomic Energy Establishment for her support and permission of using the Resistivity Meter (Saris) in this paper, moreover, deep thanks also extend to Fouzie Mohamed and Osama Osman at Geophysics Department, Science Faculty, Tripoli University for their contribution in obtaining the field data.

\section{References}

[1] O. Salem, "water resources management in Libya," April 2007 [workshop on Integrated Water Resources Management (IWRM) in Libya. Tripoli, Libya].

[2] Araguas, “Groundwater saline intrusion,” Ed Madrid Instituto Geologic, Spain, First Edition, 2005.

[3] A. Telford, "Applied Geophysics," Cambridge university press, Great Britain, First Edition, 1990. 
Mapping of Sea Water Intrusion in the Western Libyan Coast Using Geo-electrical Method: Case Study

[4] J. Jansen, "Geophysical methods to map brackish and saline water in aquifers," April 2011 [Water Resources Conf. University of Georgia, USA].

[5] A. Oteri, "Delineation of saline intrusion in the Dungeness shingle aquifer using surface geophysics," 1983 [Quart. J. Engg. Geol]. Volume 16, pp. 43-5.

[6] A. Satriani, A. loperte, V. Imbrenda, and V. Lapenna, "Geoelectrical Surveys for Characterization of the Coastal Saltwater Intrusion in Metapontum Forest Reserve (Southern Italy),” 2012 [International Journal of Geophysics]. pp. 43-5.

[7] S. Oddmund, M. Eirik, H. Eirik, and R. Noralf, "Seawater Intrusion and Fresh Groundwater Hydraulics in Fjord Delta Aquifers Inferred from Ground Penetrating Radar and Resistivity Profiles -Sunndalsora and Esebotn, Western Norway" 1994 [Journal of Applied Geophysics]. Volume 32, pp.305-319.

[8] A. Nowroozi, S. Horrocks, and Henderson, "Saltwater intrusion into the freshwater

aquifer in the eastern shore of Virginia: a reconnaissance electrical resistivity survey" 1999 [Journal of Applied Geophysics]. Volume 42, pp.1-22.

[9] S. Abdul Nassir, M. Loke, C, Lee and M, Nawawi, "Salt-water intrusion mapping by geoelectrical imaging surveys" 2000 [European Association of Geoscientists \& Engineers, Geophysical prospecting]. Volume 48, pp. 647-661.

[10] F. Shaaban, "Vertical electrical soundings or groundwater investigation in northwestern Egypt: A case study in coastal area" 2001 [Journal of African Earth Sciences]. Volume 33, pp.673-686.

[11] A. Sherif, El. Mahmoudi, H. Garamoon, A. Kacimov, S. Akram, A. Ebraheemand, and A. Shetty, "Geoelectrical and hydrogeochemical studies for delineating seawater intrusion in the Outlet of Wadi Ham, UAE” 2006 [Environmental Geology]. Volume 49, pp.536-551.

[12] M. Abdulaziz, M. Al-Bassam, and T. Hussein, "Combined geo-electrical and hydro-chemical methods to detect saltwater intrusion: A case study from southwest Saudi Arabia” 2008 [Management of Environmental Quality: An International Journal]. Volume 19, pp.179-193.

[13] D. Todd, and L. Mays, “Groundwater Hydrology,” Wiley, New York, USA,2005.

[14] F.Hany, H. Abd-Elhamid, and A. Javadi, "A Cost-Effective Method to Control Seawater Intrusion in Coastal Aquifers," J. of Water Resource Management, vol. 25, pp. 2755-2780, 2011. 